International Journal of Public Health Science (IJPHS)

Vol.6, No.2, June 2017, pp. 124 133

\title{
An Assessment of Health-Economic Burden of Obesity Trends with Population-Based Preventive Strategies in a Developed Economy
}

\author{
Prerna Bhasin \\ Founder Director, Inspire Analytics Ltd. UK
}

\section{Article Info}

\section{Article history:}

Received Mar 3, 2017

Revised May 5, 2017

Accepted May 20, 2017

\section{Keywords:}

Obesity Burden

Economic

Social

Prevention

Population Based Approaches

\begin{abstract}
The burden of obesity varies with age, ethnicity, socio-economic status and state economies. All new projections should hence accommodate population ageing, and other population changes such as immigration, health-care system reform, or technological advances for disease treatment for a comprehensible assessment of global burden. The unfordable and expensive nature for reversing the obesity tide arises from policies developed to combat obesity. Most of these approaches aim at bringing the problem under control, rather than affecting a cure, and obviously require a multi-disciplinary and intensive regimen. Prevention is the only feasible option and is essential for all affected countries. Yet it is not simple to have population based UK-wide strategic framework for tackling obesity. Besides existence of multiple layers of governance, there are clear demarcations between targets in diet; nutrition and physical activity level between regions some of which are not realistic. Population based approaches target policies and process, aiming for a transition towards healthy population diets, activity levels and weight status. It is essential to understand these aspects differ culturally and between and within countries. There are still no clear and appropriate answers about answer when, where, why, and, how costs accrue in obese populations, further long term commitments are required for the same. Most populationbased prevention policies are cost effective, largely paying for themselves through future health gains and resulting reductions in health expenditures. Therefore these prevention programs should be high on the scientific and political agendas.
\end{abstract}

Copyright $@ 2017$ Institute of Advanced Engineering and Science. All rights reserved.

\section{Corresponding Author:}

Prerna Bhasin, Founder Director, Inspire Analytics Ltd. UK, PhD, MPH (London, UK), M.Sc, PGDBA.

Institutional Id: info@inspireanalytics.co.uk

\section{INTRODUCTION}

During the past few decades, the prevalence of obesity has grown to epidemic proportions, and this condition is now known to be a major contributor to the global burden of disease [1]. Obesity is defined as a chronic disease characterised by an increase of body fat stores or an 'abnormal or excessive fat accumulation that may impair health' [2]. In clinical practice, the body fatness is assessed by the Body Mass Index (BMI) which is a derived 'marker of obesity' and is measured in $\mathrm{kg} / \mathrm{m}^{2}$.

$\mathrm{BMI}=\frac{\text { Measured body weight }(\mathrm{kg})}{\text { Measured hight }\left(\mathrm{m}^{2}\right)}$


In adults, WHO defines obesity by a $\mathrm{BMI} \geq 30$ and overweight (also termed pre-obesity) by a BMI 25-29.9 in Caucasians. Individuals found in overweight range of BMI 25-29.9 chronically, have higher odds of becoming obese in later life [3]. Cross-cultural paradigms arose in adiposity assessment when several studies reported at the same BMI level, higher body fat percentage is found in Asians than in Caucasians yet their prevalence of obesity is much lower [4]-[6]. This implied that at a certain BMI level, body fatness and fat distribution might vary across populations prompting IDF (International Diabetes Federation) and the IOTF (International Obesity Task Force) to introduce different BMI cut points for other ethnicities. Complications persisted in defining overweight and obesity among children as dynamics in change of height and weight are mostly uncertain. BMI therefore became a less reliable predictor of obesity among children before an international standard was proposed for childhood obesity using different methodologies [7].

In the last decade, BMI has been publicised as an imprecise obesity marker, as individuals with the same BMI were found to have different levels of body fat content. Recent studies indicate that abdominal obesity or visceral adiposity is significantly associated with metabolic and cardiovascular diseases and suggests that waist circumference is more closely associated with mortality and morbidity than BMI [8].

\subsection{Pathogenesis of obesity}

Obesity develops as a result of a period of chronic energy imbalance [9] and is maintained if these elevated levels of increased energy intake persist. Globalization has made the world wealthier. The consequent transition in economies has contributed to shifting dietary patterns, for example, higher per capita energy availability with increased consumption of energy-dense diets high in fat (fast-food), larger portion sizes, food consumed outside the home, greater consumption of soft drinks, and [10]-[12]. This compounded with decline in energy expenditure (sedentary lifestyle-motorized transport, labour-saving devices at home, the phasing out of physically demanding manual tasks) has led to development of obesity. Genetics account for $60-85 \%$ of the variation in obesity but if genes 'load the gun' the obesity-promoting environment 'pulls the trigger', therefore interaction between biological factors, behavioural and environmental factors together regulate energy balance and fat stores [9],[13]. UK Foresight Programme (2007) introduced the Obesity System Map to model determinants of obesity, reproducing comprehensive, complex results along similar lines [14]. Migration of populations may also account for a proportion of the epidemic.

\subsection{Consequences of obesity}

Obesity has a more pronounced impact on morbidity than mortality and severely impairs quality of life. Obesity is known to exist with its chronic co-morbidities as shown in Figure 1 like cardiovascular disease, type 2 diabetes mellitus, respiratory disorders, cancer, osteoarthritis, work disability, and sleep apnoea [1]. These together have been responsible for 38\% of all-cause mortality, $31 \%$ of years of life lost in early deaths, $12 \%$ of years of life lost in disability and $21 \%$ of DALYs disability adjusted life years in WHO EUR-A region where $7.3 \%$ of all DALYs lost were directly attributable to overweight and obesity. The World Health Report reported that obesity is responsible for between $8 \%$ and $15 \%$ of disability adjusted life years (DALYs) lost in Europe and North America [15]. Disabling effect of obesity comes through arteriosclerosis or triopathy of diabetes-nephropathy, neuropathy, and retinopathy when insulin is not sufficient [16]. As the obesity epidemic spreads, concern about the significant health and economic consequences has also grown.

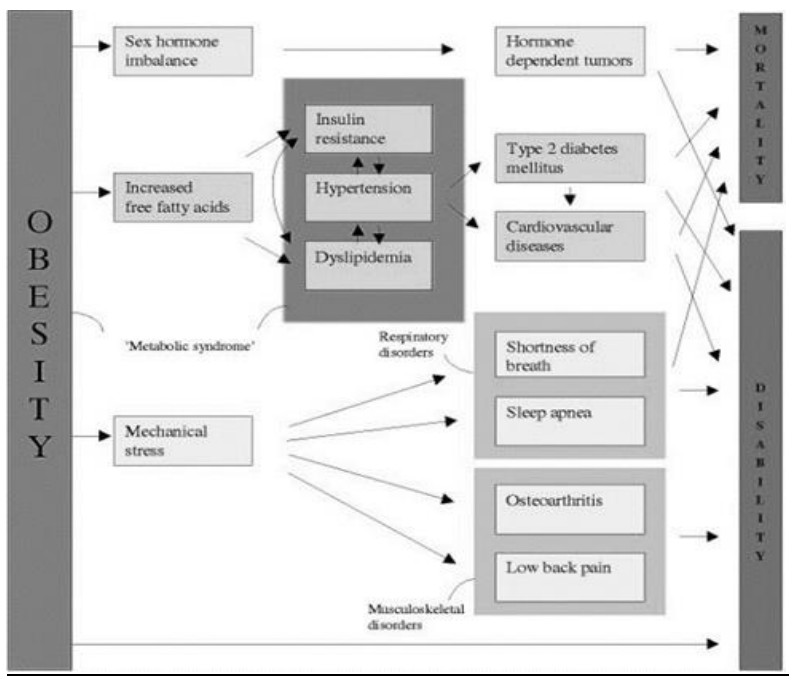

Figure 1. The Public Health Impact of Obesity, Adapted [1] 
The present review is not a standard systematic review but an attempt to find appropriate answers associated with need based assessment about when, where, why, and, how burdens accrued in obese populations of a developed economy like UK, and an overview linked the further long term commitments required.

\section{RESEARCH METHOD}

We searched articles indexed in MEDLINE and published in English 1995 and June 2014 to identify data on burdens associated with obesity in a developed economy of UK. The Medical Subject Heading (MeSH) terms "obesity" and "obesity, morbid" were combined with those for "costs and cost analysis," "economics, pharmaceutical," "economics, medical," "economics, hospital," and "work disability." The MEDLINE search returned 32 results, and 24 articles were selected for full-text review. EMBASE, International Pharmaceutical Abstracts (IPA), and Current Contents Connect (CCC) databases also were searched with similar keywords and limits; 12 additional unique articles were located, and 4 were chosen for full-text review. In addition, supplemental searches of data published on the Internet by the World Health Organization (WHO) and governmental agencies were conducted, and seven sources were selected for further consideration. For all search results, costs related to behavioral or lifestyle interventions for obesity were excluded. Of the all costrelated full-text documents reviewed, 14 studies or reports presented national or regional data in one or more regions of interest, and information from these sources is presented here. The cost data are summarized and grouped by study methodology and adapted from other studies for compartive overview. Converting all health care costs to a uniform, price-adjusted currency allows comparison of the volume of health care purchased in the different countries (without adjusting for population size differences among the countries).

\section{RESULTS AND ANALYSIS}

\subsection{Sizing the problem: epidemiological overview}

A compilation of epidemiological studies from 199 countries revealed that 1.46 adults worldwide were estimated to be overweight in 2008, and of these 502 million were obese, through systemic analysis [17]. UK is also experiencing an epidemic of overweight and obesity. The prevalence of excess weight is increasing rapidly across the country, and in 2013 close to $62 \%$ of the adult population was found to be overweight or obese [18]. A comparative trend by HSE (Health Survey for England) data documented, the prevalence of severe obesity among women increased from $1.4 \%$ in 1993 to $3.1 \%$ in 2012 and among men prevalence increased from $0.2 \%$ in 1993 to $1.7 \%$ in 2012, and is predicted to reach around $70 \%$ by 2034 . The numbers are overwhelming and are second only to the USA as shown in Figure 2. Across borders, $20 \%$ of all adults in most European countries are already obese and with higher rates often found in the Southern, Central and Eastern European nation [19]. While Middle East encounters exceptionally high obesity levels and type 2 diabetes [20], Caribbean Islands are struggling with overwhelming medical burden of premature diabetes and cardiovascular disease [21]. Asian and African countries have been hit by dual burden of diseases with soaring prevalence rates of obesity and its associated type 2 diabetes [22] elucidated by the nutrition-transition paradox [23]. Obesity in UK tends to increase with age (up to 64 years) and is more common in people with low educational attainment, low income or in manual occupations. Ethnic differences are apparent underpinning later health inequalities across Great Britain [24],[25].

A conundrum was created due to unusual genetic-environmental problems associated with obesity and differential cut-offs for BMI (which changes by age and differentially by sex) when childhood obesity trends were to be assessed. Once solved, serial increasing trends in obesity prevalence were documented in most Western countries, especially the UK and the USA. HSE figures show that the average prevalence of overweight and obesity in children aged 2-10 and 11-15 years is around 26\% and 35\% respectively [26]. 10\% of the world's school-aged children are estimated to be carrying excess body fat, quarter of which are known to have significant likelihood of some other multiple risk factors and co-morbidities before or during early adulthood. It has been reported that nearly $0.5-1 \%$ of all children are becoming overweight each year in USA, Brazil, Canada, Australia and parts of Europe [13]. 


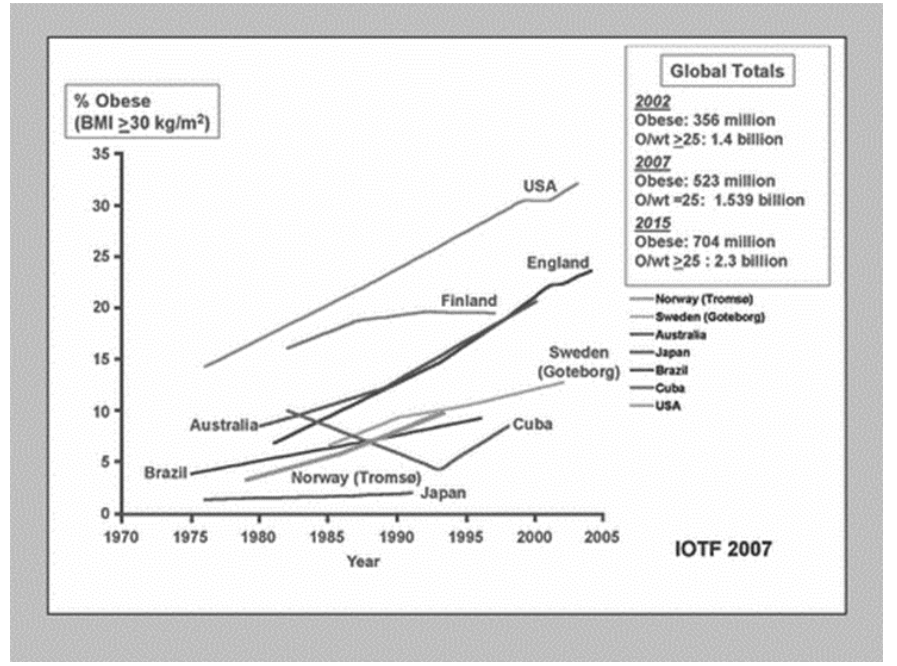

Figure 2. Analyses of the Escalating Obesity Rates in Different Countries; Adapted [19]

\subsection{Obesity as Public Health burden}

As the obesity epidemic is subjected to diverse economic and cultural landscape, so are its consequences therefore, the impact of obesity is measured as combined effect on disability and mortality as seen in Figure 2. The disabling effect of obesity or morbidity has been the focus of recent studies as population longevity has increased and it directly impacts quality of life and physical, social, and mental functioning [27],[28]. This includes osteoarthritis especially in elderly [29], infertility [30] and respiratory disorders like asthma [31].

Though studies have reaffirmed the association of high BMI levels as risk factors for all-cause mortality especially premature mortality [32] but odds were found to be higher for disease incidence, i.e., for type 2 diabetes mellitus, myocardial infarction, and ischemic stroke [1],[33] and at older ages [34]. These trends were attributed to increased cholesterol levels. The WCRF panel estimated that $30 \%-40 \%$ of all cancers are attributable to inappropriate diet, lack of physical activity, and high body weight [35]. The health burden from obesity is largely equated to benign prostate hypertrophy [36] and several other forms of cancer due to metabolic abnormalities occurring at high BMI levels. It has been reported that for males, risk for esophageal cancer increases by $52 \%$ and for colon cancer by $24 \%$ with an additional $5 \mathrm{~kg} / \mathrm{m}^{2}$ in BMI [37]. In women, relative risks augmented to $59 \%$ for endometrial cancer and by $12 \%$ for post-menopausal breast cancer [38]. In 2002, in conjunction with obesity; cancer caused $27 \%$ of mortality and $17 \%$ of DALYs lost in countries such as the UK [15]. Table 1 projects health trends based on QALY's for UK and USA. Although the prevalence of obesity in the UK is less than in the USA, a substantial disease burden is associated with obesity and overweight in the UK population. During the next 20 years, it has been projected that obesityattributable disease risks will add an excess of 544,000 - 668,000 cases of diabetes, 331,000-461,000 of coronary heart disease and strokes, and 87,000 - 130, 000 of cancer [37].

Maternal obesity has significant implications for the health of women and their babies as it is linked to an increased risk of congenital anomalies. HSE reported an increase in obesity among women of childbearing age from $12.0 \%$ in 1993 to $18.5 \%$ in 2006 [39] and has been associated with increased risks during the antenatal, intrapartum and postnatal periods incur additional demand on NHS maternity services in UK [40]. As with adults, obesity in childhood causes hypertension, dyslipidemia, chronic inflammation, increased blood clotting tendency, endothelial dysfunction, and hyper-insulinaemia and further clustering of cardiovascular disease risk factors, known as the insulin resistance syndrome, has been identified in children as young as 5 years of age [41],[42]. A British cohort study reported, 2-fold increase in mortality risk among overweight adolescents and young adults over 57 years [43]. Pediatric obesity epidemic increases odds of occurrence of Type 2 diabetes, representing noxious consequence through macro-vascular and microvascular sequelae. Psychosocial consequences of obesity are not unheard of. Overweight children as young as age 5 years can develop a negative self-image, and obese adolescents show declining degrees of self-esteem associated with sadness, loneliness, nervousness, and high-risk behaviors [41]. With life-expectancy showing an upward trend, and increase in prevalence of obesity at a much younger age the morbidity statistics are going to rise through chronic disabilities further escalating the associated costs. 
Table 1. Projected Health and Quality-Adjusted Life-Year Outcomes 2010-30; adapted [37]

\begin{tabular}{|c|c|c|c|c|}
\hline \multirow{2}{*}{$\begin{array}{l}\text { Projected health and quality-adjusted life-year outcomes } \\
2010 \text { - } 30 \text { under three hypothetical scenarios of } \\
\text { population-wide change in body-mass index distribution }\end{array}$} & \multicolumn{2}{|l|}{ UK } & \multicolumn{2}{|c|}{ USA } \\
\hline & Recent trend & Historic trend & Recent trend & Historic trend \\
\hline \multicolumn{5}{|c|}{ Scenario 1. Past trends continue unabated } \\
\hline Coronary heart disease and stroke $(\times 1000)$ & $+331(407)$ & $+461(128)$ & $+5365(3359)$ & +6836 \\
\hline Cancer $(\times 1000)$ & $+87(108)$ & $+130(34)$ & $+405(265)$ & $+539(123)$ \\
\hline Gain or loss in QALYs $(\times 1000)$ & -2219 & -6300 & -24488 & -48259 \\
\hline \multicolumn{5}{|c|}{ Scenario $2.1 \%$ reduction in BMI for every adult at baseline } \\
\hline Coronary heart disease and stroke $(\times 1000)$ & $-122(374)$ & $-122(116)$ & $-1431(2799)$ & -170 \\
\hline Cancer $(\times 1000)$ & $-32(100)$ & $-33(33)$ & $-73(219)$ & 109) \\
\hline Gain or loss in QALYs $(\times 1000)$ & $+3011(930)$ & $+3195(395)$ & +15988(1911) & $+16135(781)$ \\
\hline \multicolumn{5}{|c|}{ Scenario 3. If obesity rates had remained at 1990 levels } \\
\hline Diabetes $(\times 1000)$ & $-897(216)$ & $-1021(159)$ & $-8664(3524)$ & $-11016(1618)$ \\
\hline Coronary heart disease and stroke $(\times 1000)$ & $-634(204)$ & $-763(128)$ & $-7670(3359)$ & $-9141(1537)$ \\
\hline Cancer $(\times 1000)$ & $-177(54)$ & $-220(34)$ & $-534(265)$ & $-668(123)$ \\
\hline
\end{tabular}

\subsection{Obesity as an Economic burden}

Obesity not only threatens the wellbeing of individuals due to its association with numerous chronic and acute health disorders [44] but also by incurring substantial costs to the individuals affected and to society, notably from increased health-care costs and lost productivity [37]. Obesity places a burden on public resources in terms of health costs, on employers through lost productivity and on families because of the increasing burden of long-term chronic disability, imposing huge gaps in health and social care [14]. Quantification of the costs from the health consequences of obesity is complex; costs are mediated by factors such as a changing demography, food system, and the economy. The medical costs include management of obesity and use of ambulatory care, hospitalisation, drugs, radiological or laboratory tests, and long term care. In addition to medical costs, society incurs substantial indirect costs from obesity as a result of decreased DALY's, premature mortality (before retirement), economic load of early retirement, disability pensions, and work absenteeism or reduced productivity [37]. In US, these figures totaled to an equivalent of 1 month of lost productivity and cost employers $\$ 3792$ per year [45].

In early $20^{\text {th }}$ century, obesity accounted for $2 \%$ of health-care costs in France and Australia and nearly $4 \%$ in the Netherlands, while in 2003 health-care costs associated with obesity accounted for 4-7\% of total expenditure in US [37],[45]. The total cost of CVD to the UK economy is estimated as $£ 30$ billion, $60 \%$ due to health-care costs [46]. In 2006-07, 46\% of total NHS costs (over $£ 43$ billion) were due to diseases related to poor diet, physical inactivity, smoking, alcohol and overweight/obesity as shown in Table 2. Of the behavioral risk factors, over $£ 5$ billion was spent on overweight/ obesity-related ill health, although this includes costs from poor diet and physical inactivity [47]. In 2007, it was projected 'Tackling Obesities: Future Choices', that the continuing rise in obesity will add $£ 5 \cdot 5$ billion in medical costs to the National Health Service by 2050 [14].

The economic consequences of childhood obesity are not limited to direct costs, such as medical costs, and indirect, such as job absenteeism but incur later when obese children become obese adults. The estimated annual cost of treating obesity-related illness in adults is $\$ 147$ billion and has risen by 27 percent between 1987 and 2001. As obesity is associated with delayed skill acquisition, it is also found to be associated with lower wages, in later life [48].

If trends are to be believed, further increases in obesity in the UK and USA projects an expansion of obesity-related and mostly chronic diseases with substantial implications for health-care expenditure. Compounded by an ageing population, a substantial health-care cost burden is expected in the UK. This projection implies $£ 648$ million higher costs annually in 2020 and $£ 2$ billion higher costs annually in 2030 will be spent on treating obesity-related diseases [37]. Similar trends have been reported in US but it has been suggested that most estimates are over-reported as increased mortality among obese people may result in a $25 \%$ overestimate of direct healthcare costs when using population attributable fraction in cost estimates [49]. These estimates of the economic cost of risk factors for chronic disease to the NHS provide evidence for prioritization of resources for prevention and public health. 
Table 2. Original and Updated Economic Costs of Overweight/Obesity to the NHS, Adapted [47]

\begin{tabular}{|c|c|c|c|c|c|}
\hline \multirow{2}{*}{$\begin{array}{c}\text { Disease Burden and co- } \\
\text { morbidities }\end{array}$} & \multicolumn{2}{|c|}{$\%$ of total NHS costs } & \multirow[b]{2}{*}{ PAF } & \multicolumn{2}{|c|}{ Total NHS costs (£millions) } \\
\hline & $1992-1993$ & 2006-2007 & & Original costs (2002) & Updated costs $(2006-07)$ \\
\hline Ischemic stroke & 4.1 & 1.2 & 34 & 983 & 332 \\
\hline Colon/rectum cancer & 0.5 & 0.5 & 16 & 61 & 65 \\
\hline Hypertensive disease & 1.4 & 4.5 & 58 & 576 & 2121 \\
\hline Corpus uteri cancer & 0.1 & 0.2 & 49 & 41 & 80 \\
\hline Osteoarthritis & 1.6 & 5.0 & 21 & 229 & 853 \\
\hline Total & 11.6 & 16.2 & & 3231 & 5146 \\
\hline
\end{tabular}

\subsection{Reversing the tide: Prevention holds the key}

The unfordable and expensive nature for reversing the obesity tide arises from policies developed to combat obesity. Most of these approaches aim at bringing the problem under control, rather than affecting a cure, and obviously require a multi-disciplinary and intensive regimen. Pharmaceutical approaches may assist, but cannot replace, the multidisciplinary management of obesity [13]. Prevention is the only feasible option and is essential for all affected countries. Developing public health preventive policies to combat obesity is also a much more complex process than anticipated as there are all sorts of political pressures to cope with [19]. There is a wide gap between recommendations and implementation due to political, economic and cultural factors. The rising epidemic reflects the profound changes in society and in behavioural patterns of communities. Therefore, most policies should be woven around communities with new regulatory approaches towards behaviour changes at multiple settings and at all levels of government as seen in Figure 3. Some key policy interventions based on 'drivers of obesity' theories have been tabulated in Table 3.

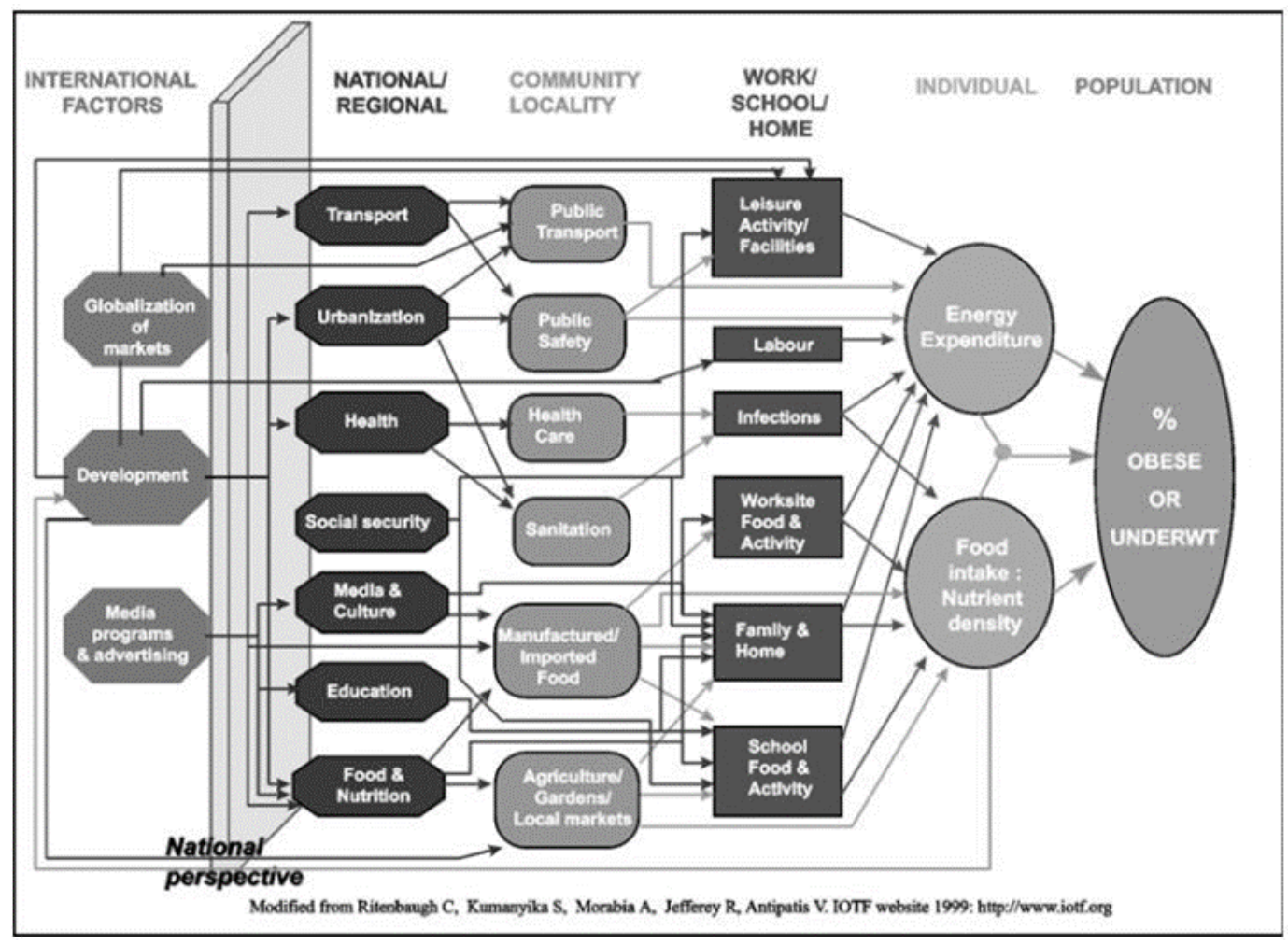

Figure 3. Population Level Policies with Direct and Indirect Influences on The Prevalence of Obesity; Links will Vary between Different Societies and Populations, Adapted [50] 
Table 3. The Policy Implications of some Key Theories, Adapted [51]

\begin{tabular}{|c|c|c|}
\hline Theory & Core argument & Implied solutions \\
\hline Genetic causation & $\begin{array}{l}\text { The predisposition to lay down fat is an } \\
\text { evolutionary legacy }\end{array}$ & $\begin{array}{c}\text { Genomics, gene mapping and nutrigenomics. Functional } \\
\text { foods might help play a part in tailoring diets to individual } \\
\text { predispositions }\end{array}$ \\
\hline Economic transition & $\begin{array}{c}\text { Lifestyle change is associated with } \\
\text { development of a post-industrial } \\
\text { consumerist society }\end{array}$ & $\begin{array}{l}\text { Once sufficiently affluent, people will be able to tackle } \\
\text { obesity as consumers, choosing or not, as they wish. At the } \\
\text { micro level, fiscal measures such as 'fat taxes' could be } \\
\text { considered }\end{array}$ \\
\hline Technological change & $\begin{array}{c}\text { Oil as a source of energy is replacing food as } \\
\text { source of energy }\end{array}$ & $\begin{array}{l}\text { Build in more physical energy use into daily life. Design } \\
\text { technology to help keep intake in balance with expenditure }\end{array}$ \\
\hline Cultural change & $\begin{array}{c}\text { Marketing and advertising instils new cultural } \\
\text { norms about what and how to eat, and how } \\
\text { much to eat }\end{array}$ & Social marketing can emulate 'business' marketing \\
\hline Psychosocial & $\begin{array}{l}\text { Food choice is intensely personal and } \\
\text { expresses identity. Obesity suggests a schism } \\
\text { within identity well-being }\end{array}$ & $\begin{array}{l}\text { Family change. Counselling. This is required both } \\
\text { individually and on a mass scale }\end{array}$ \\
\hline Obesogenic environment & $\begin{array}{l}\text { Obesity is a normal physiological response to } \\
\text { an abnormal or inappropriate environment }\end{array}$ & $\begin{array}{l}\text { Change the physical and dietary environments to allow } \\
\text { normal physiological balance to(re)emerge }\end{array}$ \\
\hline Nutrition transition & $\begin{array}{l}\text { Rising income leads to dietary changes, } \\
\text { leading to shifts in disease patterns }\end{array}$ & It is probably too late to prevent rising obesity \\
\hline
\end{tabular}

\subsection{Population level Approaches}

Diet and Nutrition: Focusing of nutritional needs of a population archives the ultimate goal of improving population health Targeting diet and nutrition mean focusing on decreasing the intake of non-milk extrinsic sugars and salt and increasing the consumption of fruit and vegetables (to at least 5 portions a day). Addressing issues such as fair trade, economic viability and accessibility and affordability, UK Action plan recommends changes in the supply chain such as increasing consumer demand for healthy food, giving people a better understanding of healthy eating through training, improving food labelling and influencing those who govern and monitor changes in health. Although there have been improvements in food environment and dietary intake some areas, no real-life evidence exists linking these changes with measured changes in body weight in adults [52] or BMI in children [53]. A new regime here would be introduction to "fat tax" over salt- and fat-enriched food items.

Social Marketing: Providing accurate and balanced information' to the general population regarding diet and nutrition as well as physical activity. Social marketing is said to be the most effective strategy for both children and adults as it ranges from raising awareness through mass media campaigns, improving adult literacy and cooking competency skills to marketing strategies that increase awareness about unhealthy choices [14]. Physical Activity Levels: All regions have set targets to increase physical activity with England setting the most ambitious target of having 70 percent of adults meet the recommended levels of activity by 2020 and Scotland, 50 percent of Scottish adults by 2022 [54]. Interventions involving built environment, sports clubs and enhanced access, schools, and workplace have resulted in positive outcomes. The most efficient interventions to increase physical activity were community rail-trails, pedometers, and school health education programs and seem to increase physical activity cost-effectively [55]. This strategy has been more effective children.

Community design and infrastructure characteristics ("built environment") have become increasingly prominent in efforts to identify population-level determinants of obesity. Urban "sprawl" is a geographic concept that has recently been studied in relation to risk of obesity and results in large areas of low-population density that encourage and usually require residents to drive from home to work, stores, school, and recreation facilities. Interventions based in schools, work-place, health accommodations and communities are next in line to combat obesity by targeting obesogenic environments.

A new policy-Life Course Approach: Policy interventions to tackle obesity in the devolved regions have been primarily aimed at preventing childhood obesity. This focus has neglected tackling obesity in adulthood and yet age is a significant risk factor for obesity with most obese individuals being adults who account for the majority of obesity-related financial costs. The only approach that combines 'tracking' of conventional risk factors from childhood to adulthood; integrates evidence for 'programming' as a potential model of disease etiology with, in particular, 'the fetal origins of adult disease' hypothesis [56]; and focuses on critical periods might the most cost-effective and feasible approach for many countries and should involve three mutually reinforcing strategies throughout life, starting in the antenatal period.

It is not simple to have population based UK-wide strategic framework for tackling obesity. Besides existence of multiple layers of governance, there are clear demarcations between targets in diet; nutrition and physical activity level between regions some of which are not realistic. Social media and marketing strategy 
fails due to distorted perceptions of what qualifies as normal and excess body weight, particularly in relation to the parents of overweight and obese children, have been found to be a significant issue. Managing and sustaining food and nutrition or physical activity policy has its own fiscal limits. Success of these policies and processes are embedded in different sectors-political, economic and social structural levels. Interventions aimed at improving individual lifestyles, have limited access in some areas and this may actually aggravate disparities between the more and less advantaged. Population based approaches target policies and process, aiming for a transition towards healthy population diets, activity levels and weight status. It is essential to understand these aspects differ culturally and between and within countries. Although the beneficial results of such interventions may be long-term, detectable and significant, they are sometimes very small compared with the size of the problem. Moreover, the improvements tend to decline after the intervention ends. It must be concluded that interventions will need a co-ordinated effort by stakeholders at the family or school level, and are to be matched by changes in the social and cultural context so that the benefits can be sustained and enhanced.

\section{CONCLUSION}

The burden of obesity varies with age, ethnicity, socio-economic status and state economies. All new projections should hence accommodate population ageing, and other population changes such as immigration, health-care system reform, or technological advances for disease treatment for a comprehensible assessment of global burden. There are still no clear and appropriate answers about answer when, where, why, and, how costs accrue in obese populations, further long term commitments are required for the same. Most population-based prevention policies are cost effective, largely paying for themselves through future health gains and resulting reductions in health expenditures. Therefore, these prevention programs should be high on the scientific and political agendas. It is hence, essential to evaluate these policies in new light for all economies and with revived interests for its widespread adverse health consequnces.

\section{REFERENCES}

[1] Visscher T. L. and Seidell J. C., "The Public Health Impact of Obesity," Annual Review of Public Health, vol/issue: 22(1), pp. 355-75, 2001.

[2] WHO, "World Health Organization: Obesity and overweight," Fact Sheet, pp. 9, 2006.

[3] Field A. E., et al., "Impact of overweight on the risk of developing common chronic diseases during a 10-year period," Archives of internal medicine, vol/issue: 161(13), pp. 1581-6, 2001.

[4] Wen C. P., et al., "Are Asians at greater mortality risks for being overweight than Caucasians? Redefining obesity for Asians," Public health nutrition, vol/issue: 12(04), pp. 497-506, 2009.

[5] Ko G. T., et al., "Lower BMI cut-off value to define obesity in Hong Kong Chinese: an analysis based on body fat assessment by bioelectrical impedance," British Journal of Nutrition, vol/issue: 85(02), pp. 239-42, 2001.

[6] Y. M. Deurenberg, et al., "Elevated body fat percentage and cardiovascular risks at low body mass index levels among Singaporean Chinese, Malays and Indians," Obesity Reviews, vol/issue: 3(3), pp. 209-15, 2002.

[7] Cole T. J., et al., "Establishing a standard definition for child overweight and obesity worldwide: international survey," Bmj, vol/issue: 320(7244), pp. 1240, 2000.

[8] Price G. M., et al., "Weight, shape, and mortality risk in older persons: elevated waist-hip ratio, not high body mass index, is associated with a greater risk of death," The American journal of clinical nutrition, vol/issue: 84(2), pp. 449-60, 2006.

[9] F. Hainer, et al., "Management of obesity in adults: project for European primary care. International journal of obesity and related metabolic disorders," Journal of the International Association for the Study of Obesity, vol/issue: 28(1), pp. S226-31, 2004.

[10] Stein C. J. and Colditz G. A., "The Epidemic of Obesity," The Journal of Clinical Endocrinology \& Metabolism, vol/issue: 89(6), pp. 2522-5, 2004.

[11] Harnack L. J., et al., "Temporal trends in energy intake in the United States: an ecologic perspective," The American journal of clinical nutrition, vol/issue: 71(6), pp. 1478-84, 2000.

[12] Popkin B. M., "The nutrition transition and its health implications in lower-income countries," Public health nutrition, vol/issue: 1(01), pp. 5-21, 1998.

[13] Lobstein T., et al., "Obesity in children and young people: a crisis in public health," Obesity Reviews, vol. 5, pp. 4$85,2004$.

[14] Butland B., et al., "Foresight. Tackling obesities: future choices. Project report," Foresight Tackling obesities: future choices Project report, 2007.

[15] Allender S. and Rayner M., "The burden of overweight and obesity- related ill health in the UK," Obesity reviews, An Assessment of Health Economic Burden of Obesity Trends with Population Based... (Prerna Bhasin) 
vol/issue: 8(5), pp. 467-73, 2007.

[16] DeFronzo R. A. and Ferrannini E., "Insulin resistance: a multifaceted syndrome responsible for NIDDM, obesity, hypertension, dyslipidemia, and atherosclerotic cardiovascular disease," Diabetes care, vol/issue: 14(3), pp. 17394, 1991

[17] Finucane M. M., et al., "National, regional, and global trends in body-mass index since 1980: systematic analysis of health examination surveys and epidemiological studies with 960 country-years and $9 \cdot 1$ million participants," The Lancet, vol/issue: 377(9765), pp. 557-67, 2011.

[18] PHE, “Adult Weight data factsheet, August 2014: Health Survey for England England, UK2014” [cited 2015 April 16]. Available from: http://www.noo.org.uk/NOO_pub/Key_data.

[19] James W. P. T., "The epidemiology of obesity: the size of the problem," Journal of Internal Medicine, vol/issue: 263(4), pp. 336-52, 2008.

[20] Wild S., et al., "Global prevalence of diabetes estimates for the year 2000 and projections for 2030," Diabetes care, vol/issue: 27(5), pp. 1047-53, 2004.

[21] Johnson R. J., et al., "Potential role of sugar (fructose) in the epidemic of hypertension, obesity and the metabolic syndrome, diabetes, kidney disease, and cardiovascular disease," The American journal of clinical nutrition, vol/issue: 86(4), pp. 899-906, 2007.

[22] Prentice A. M., "The emerging epidemic of obesity in developing countries," International Journal of epidemiology, vol/issue: 35(1), pp. 93-9, 2006.

[23] Doak C. M., et al., "The dual burden household and the nutrition transition paradox," International journal of obesity, vol/issue: 29(1), pp. 129-36, 2005.

[24] Jebb S. A., et al., "Prevalence of overweight and obesity among young people in Great Britain," Public Health Nutr., vol/issue: 7(3), pp. 461-5, 2004.

[25] Rennie K. L. and Jebb S. A., "Prevalence of obesity in Great Britain," Obesity Reviews, vol/issue: 6(1), pp. 11-2, 2005.

[26] PHE, "Child Weight data factsheet, August 2014: Health Survey for England England, UK,” 2014

[27] Fries J. F., "Aging, natural death, and the compression of morbidity," Bulletin of the World Health Organization, vol/issue: 80(3), pp. 245-50, 2002.

[28] Lissner L., "Causes, diagnosis and risks of obesity," Pharmacoeconomics, vol/issue: 5(1), pp. 8-17, 1994.

[29] Guh D. P., et al., "The incidence of co-morbidities related to obesity and overweight: a systematic review and metaanalysis," BMC public health, vol/issue: 9(1), pp. 88, 2009.

[30] Withrow D. and Alter D., "The economic burden of obesity worldwide: a systematic review of the direct costs of obesity," Obesity reviews, vol/issue: 12(2), pp. 131-41, 2011.

[31] Thorpe K. E., et al., "The impact of obesity on rising medical spending," Health Affairs-Millwood Va Then Bethesda Ma, vol. 23, pp. 283, 2004

[32] Manson J. E., et al., "Body weight and longevity: a reassessment,” Jama, vol/issue: 257(3), pp. 353-8, 1987.

[33] Manson J. E., et al., "Body weight and mortality among women," New England Journal of Medicine, vol/issue: 333(11), pp. 677-85, 1995.

[34] Stevens J., et al., "The effect of age on the association between body-mass index and mortality," New England Journal of Medicine, vol/issue: 338(1), pp. 1-7, 1998.

[35] WCRF, “American Institute for Cancer Research and World Cancer Research Fund International: Food, nutrition and the prevention of cancer: a global perspective: American Institute for Cancer Research," 1997.

[36] Nichols M., et al., "Decreasing trends in overweight and obesity among an Australian population of preschool children," International Journal of Obesity, vol/issue: 35(7), pp. 916-24, 2011.

[37] Wang Y. C., et al., "Health and economic burden of the projected obesity trends in the USA and the UK," The Lancet, vol/issue: 378(9793), pp. 815-25, 2011.

[38] Renehan A. G., et al., "Body-mass index and incidence of cancer: a systematic review and meta-analysis of prospective observational studies," The Lancet, vol/issue: 371(9612), pp. 569-78, 2008.

[39] CEMACH, "Confidential enquiry into maternal and child health,” London, Perinatal Mortality, 2005.

[40] Heslehurst N., et al., "A nationally representative study of maternal obesity in England, UK: trends in incidence and demographic inequalities in 619[thinsp]323 births, 1989-2007,: Int J Obes., vol/issue: 34(3), pp. 420-8, 2010.

[41] Ebbeling C. B., et al., "Childhood obesity: public-health crisis, common sense cure," The Lancet, vol/issue: 360(9331), pp. 473-82, 2002.

[42] Young H. D., et al., "Evaluation of the insulin resistance syndrome in 5-to 10-year-old overweight/obese AfricanAmerican children," Diabetes care, vol/issue: 24(8), pp. 1359-64, 2001.

[43] Gunnell D. J., et al., "Childhood obesity and adult cardiovascular mortality: a 57-y follow-up study based on the Boyd Orr cohort," The American journal of clinical nutrition, vol/issue: 67(6), pp. 1111-8, 1998. 
[44] Muennig P., et al., "Gender and the burden of disease attributable to obesity," American Journal of Public Health, vol/issue: 96(9), pp. 1662-8, 2006.

[45] Finkelstein E. A., et al., "The costs of obesity in the workplace," Journal of Occupational and Environmental Medicine, vol/issue: 52(10), pp. 971-6, 2010.

[46] Luengo F. R., et al., "Cost of cardiovascular diseases in the United Kingdom,” Heart, vol/issue: 92(10), pp. 1384-9, 2006.

[47] Scarborough P., et al., "The economic burden of ill health due to diet, physical inactivity, smoking, alcohol and obesity in the UK: an update to 2006-07 NHS costs," Journal of Public Health, vol/issue: 33(4), pp. 527-35, 2011.

[48] Cawley J., "The Economics Of Childhood Obesity," Health Affairs, vol/issue: 29(3), pp. 364-71, 2010.

[49] Allison D. B., et al., "The direct health care costs of obesity in the United States," Am J Public Health, vol/issue: 89(8), pp. 1194-9, 1999.

[50] Kumanyika S., et al., "Public Health Approaches to the Prevention of Obesity (PHAPO) Working Group of the International Obesity Task Force (IOTF)," International journal of obesity, vol. 26, pp. 425-36, 2002.

[51] Musingarimi P., "Obesity in the UK: A review and comparative analysis of policies within the devolved administrations," Health policy, vol/issue: 91(1), pp. 10-6, 2009.

[52] Storcksdieck G. B. S. and Wills J. M., "Nutrition Labeling to Prevent Obesity: Reviewing the Evidence from Europe," Current Obesity Reports, vol/issue: 1(3), pp. 134-40, 2012.

[53] Jaime P. C. and Lock K., "Do school based food and nutrition policies improve diet and reduce obesity?" Preventive medicine, vol/issue: 48(1), pp. 45-53, 2009.

[54] Smith O., "Healthy Weight, Healthy Lives: a Cross-Government Strategy for England," 2008.

[55] Laine J., et al., "Cost-Effectiveness of Population-Level Physical Activity Interventions: A Systematic Review," American Journal of Health Promotion, vol/issue: 29(2), pp. 71-80, 2014.

[56] Darnton H. I., et al., "A life course approach to diet, nutrition and the prevention of chronic diseases," Public Health Nutr., vol/issue: 7(1A), pp. 101-21, 2004.

\section{BIOGRAPHIES OF AUTHORS}

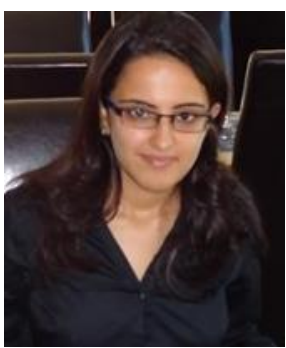

Dr. Bhasin is the founding director of a statistical consulting firm registered and based out of London, UK. She with her firm takes pride in providing academic and research centric solutions ranging from statistical and writing consulting, to technical endorsement with quantitative and qualitative analyses especially in social and health sciences. She is a social epidemiologist whose work focuses extensively on psychosocial and biological determinants of health outcomes. Her research has been oriented towards understanding social inequalities in health related to socioeconomic status, different racial and ethnic groups, and maternal-child health along with understanding chronic burden as an outcome of these mechanisms. Majority of her work is devoted to constructing a model based on life course conceptual framework for chronic diseases and suggesting evaluation of health outcomes systematically in child health through maternal parameters. She believes in through understanding of the most vulnerable phases in women's life cycle-menarche, pregnancy and senescence of reproductive phase for assessing maternal-child health outcomes. Dr. Bhasin received her PhD from University of Delhi in India, and her MPH from Kings College London, UK. 